\title{
Deficient Type I Protein Kinase A Isozyme Activity in Systemic Lupus Erythematosus T Lymphocytes
}

\author{
Gary M. Kammer, ${ }^{\star \ddagger}$ Islam U. Khan, * and Charles J. Malemud ${ }^{\ddagger}$ \\ *Department of Internal Medicine, The Bowman Gray School of Medicine of Wake Forest University, Winston-Salem, North Carolina \\ 27157; and ${ }^{\ddagger}$ Department of Medicine, Case Western Reserve University School of Medicine, Cleveland, Ohio 44106
}

\section{Abstract}

Systemic lupus erythematosus (SLE) is an autoimmune disorder of indeterminate etiology characterized by a dysfunctional cellular immune response. We have previously identified a metabolic disorder of the adenylate cyclase/cAMP/ protein kinase A (AC/cAMP/PKA) pathway characterized by impaired cAMP-inducible, PKA-catalyzed protein phosphorylation in intact $T$ lymphocytes from subjects with severe SLE disease activity. Because this metabolic disorder may contribute to abnormal $T$ cell immune effector functions, we tested the hypothesis that impaired PKA-dependent protein phosphorylation is the result of a PKA isozyme deficiency in SLE T lymphocytes. Compared with healthy and rheumatoid arthritis (RA) controls, subjects with severe SLE activity exhibited reduced PKA-catalyzed phosphorylation of proteins in the $T$ lymphocyte plasma membrane where the type I isozyme of PKA (PKA-I) is predominantly localized. Both silver staining and biosynthetic labeling of membrane-associated proteins with $\left[{ }^{35} \mathrm{~S}\right]$ methionine demonstrated that reduced protein phosphorylation was not due to either an altered distribution of or absence of proteins. Moreover, phosphorylation of SLE membrane-associated proteins with the PKA catalytic (C) subunit showed a similar distribution and extent of phosphorylation compared with membrane proteins from healthy $T$ cells, suggesting that SLE $T$ cell membrane proteins could be phosphorylated. Sequential column chromatography of the type I and type II isozymes of PKA (PKAI, PKA-II) demonstrated a deficiency of PKA-I isozyme activity. Compared with a ratio of PKA-I to PKA-II activity of $4.2: 1$ in healthy $T$ cells, the activity ratio in $T$ cells from subjects with severe SLE disease activity was 0.99:1 ( $P$ $=0.01$, SLE versus healthy controls for PKA-I). The deficient PKA-I activity was associated with a significant increase of free $C$-subunit activity $(P=0.04$, SLE versus healthy controls for $C$-subunit). $T$ cells from subjects with

Address correspondence to Dr. Gary M. Kammer, Section on Rheumatology, The Bowman Gray School of Medicine, Wake Forest University, Medical Center Boulevard, Winston-Salem, NC 27157-1058.

Received for publication 9 February 1993 and in revised form 29 March 1994.

J. Clin. Invest.

(C) The American Society for Clinical Investigation, Inc. 0021-9738/94/07/0422/09 \$2.00

Volume 94, July 1994, 422-430 mild/moderate SLE disease activity also exhibited diminished PKA-I activity, yielding a ratio of PKA-I to PKAII activity of $2.4: 1$. By contrast, $T$ cells from $R A$ controls possessed increased PKA-I, PKA-II, and free C-subunit activities compared with healthy controls, resulting in a ratio of PKA-I to PKA-II activity of 3.6:1. We conclude that the reduced PKA-catalyzed protein phosphorylation in the plasma membrane of SLE $T$ cells is the result of deficient PKA-I isozyme activity. This is the first identification of a deficiency of PKA activity in SLE T lymphocytes; the deficiency, resulting in diminished protein phosphorylation, may alter cellular homeostasis, contributing to the cellular immune dysfunctions observed in SLE. (J. Clin. Invest. 1994. 94:422-430.) Key words: systemic lupus erythematosus • T lymphocyte - protein kinase $A \cdot$ cyclic adenosine monophosphate $\cdot$ signal transduction

\section{Introduction}

Systemic lupus erythematosus (SLE) is an autoimmune disorder of indeterminate etiology that is characterized by a dysfunctional cellular immune response $(1,2)$. We have hypothesized that the diverse cellular immune dysfunctions observed in SLE (3-7) may reflect a defect of intracellular signal transduction that results in impaired immune effector functions, including suppressor activity, cytotoxicity, and mitogenesis $(1,8,9)$.

The adenylate cyclase/cAMP/protein kinase $\mathrm{A}(\mathrm{AC} /$ cAMP/PKA) ${ }^{1}$ pathway is a signal transduction system comprised of a sequence of molecules whose function is to convey biochemical signals from surface receptors to PKA. PKA phosphorylates target proteins within discrete compartments of the cell $(10,11)$. Efficient operation of this pathway requires that the second messenger, cAMP, be generated in response to a ligand/receptor-initiated signal that activates AC and catalyzes conversion of ATP to CAMP. The binding of cAMP to the regulatory $(R)$ subunits of PKA activates the enzyme by dissociating the $R$-subunits from the catalytic $(C)$ subunits, freeing C-subunits to phosphorylate proteins. PKA is the only known intracellular receptor for cAMP; it is comprised of two isozymes, termed type I (PKA-I) and type II (PKA-II) (11), which are localized predominantly to the plasma membrane and cytosol, respectively, in human T lymphocytes (12). Protein

1. Abbreviations used in this paper: $\mathrm{AC}$, adenylate cyclase; $\mathrm{C}$-subunits, catalytic subunits; 2-D PAGE, two-dimensional SDS-PAGE; $K_{\mathrm{a}}$, association constant; PKA, protein kinase A; PKA-I and PKA-II, type I and type II isozyme of PKA; R-subunits, regulatory subunits; SLEDAI, Systemic Lupus Erythematosus Disease Activity Index. 
phosphorylation is currently the only known mechanism by which the enzyme mediates its physiologic function (11).

The AC/cAMP/PKA pathway participates in the regulation of physiologic immune effector functions in $\mathrm{T}$ lymphocytes (13). The process of $\mathrm{T}$ lymphocyte activation induces the activation of protein tyrosine kinases (14), PKC isozymes (15), and the membrane-associated PKA-I isozyme (16). The activation of these and other protein kinases phosphorylates transcription factors, leading to the transcription of multiple genes, secretion of cytokines, and expression of cytokine receptors that ultimately results in mitosis. In addition to its regulatory function of immune effector activities, the AC/cAMP/PKA pathway also controls other homeostatic activities, including mobility of cell-surface molecules within the plane of the plasma membrane (17), T cell-mediated cytotoxicity (18), and cytokine secretion (18-20).

T lymphocytes from subjects with severe SLE activity have a metabolic disorder of the AC/cAMP/PKA pathway that is characterized by markedly diminished cAMP-inducible, PKAcatalyzed protein phosphorylation $(8,21)$. By contrast, no abnormality of PKA-dependent protein phosphorylation is observed in the $\mathrm{T}$ cells from rheumatic disease controls (21). This disorder may contribute to the impaired suppressor $\mathrm{T}$ cell activity and abnormal capping of T cell-surface molecules observed in both active and inactive $\operatorname{SLE}(8,9,22,23)$. Thus, we tested the hypothesis that diminished PKA-catalyzed protein phosphorylation is the result of a PKA isozyme deficiency. Our results demonstrate that T lymphocytes from patients with SLE have a deficiency of PKA-I isozyme activity.

\section{Methods}

Patient and control populations. 15 SLE subjects ( $n=14$ females, 1 male; 10 white, 5 black; mean age, 35 yr [range 28-54]) with mild ( $n$ $=6)$, moderate $(n=4)$, and severe disease $(n=5)$ activity were studied. All subjects fulfilled the criteria for the classification of SLE (24). Disease activity was quantified by the Systemic Lupus Erythematosus Disease Activity Index (SLEDAI) (25). Mild disease activity was defined as involvement of two or less organ systems and a SLEDAI score of $\leq 10$. The sera from these SLE subjects had an ANA titer $>1: 160$ (range 1:160-1:1,280), no anti-native DNA autoantibodies by RIA (normal $<7 \mathrm{U} / \mathrm{ml}$ ), and either normal or low levels of $\mathrm{C} 4$ and/or C3 complement components $(\mathrm{C} 4=8-38 \mathrm{mg} / \mathrm{dl}, \mathrm{C} 3=47-145$ $\mathrm{mg} / \mathrm{dl}$ ). Moderate disease activity was defined as involvement of two or three organ systems and a SLEDAI score of 11-20. The sera from these SLE subjects had an ANA titer $>1: 320$ (range 1:320-1:10,280), anti-native DNA autoantibodies by RIA of $>16 \mathrm{U} / \mathrm{ml}$ (range 16-152 $\mathrm{U} / \mathrm{ml}$ ), and either normal or low levels of $\mathrm{C} 4$ and/or C3 complement components $(\mathrm{C} 4=6-45 \mathrm{mg} / \mathrm{dl}, \mathrm{C} 3=37-140 \mathrm{mg} / \mathrm{dl})$. Severe SLE activity was defined as involvement of three or more organ systems and a score $\geq 21$. The sera from these SLE subjects had an ANA titer $>1: 640$ (range 1:640-1:10,280), anti-native DNA autoantibodies $>85 \mathrm{U} / \mathrm{ml}$ (range $85-554 \mathrm{U} / \mathrm{ml}$ ), and hypocomplementmia $(\mathrm{C} 4<12$ $\mathrm{mg} / \mathrm{dl}$, range $4-12 \mathrm{mg} / \mathrm{dl}$ [normal $15-45 \mathrm{mg} / \mathrm{dl}$ ], C3 $<79 \mathrm{mg} / \mathrm{dl}$, range $34-79 \mathrm{mg} / \mathrm{dl}$ [normal $89-153 \mathrm{mg} / \mathrm{dl}$ ]). Subjects with mild or moderate SLE activity had a mean of 2.0 and 2.3 affected organ systems and a mean SLEDAI score of 7.0 and 13.0, respectively. Subjects with severe SLE activity had a mean of 5.0 affected organ systems and a mean SLEDAI score of 29.0.

Newly diagnosed subjects were studied before therapy (21). Subjects experiencing a severe flare of SLE activity were studied before initiation of immunosuppressive therapy; none had been treated with immunosuppressive agents for at least $3 \mathrm{mo}$. Only SLE subjects treated with low dose corticosteroids ( $\leq 10 \mathrm{mg} / \mathrm{d}$ prednisone) were entered into this study; these subjects were studied $24 \mathrm{~h}$ after their last dose.
Table I. Characteristics of SLE and Control Populations

\begin{tabular}{|c|c|c|c|c|}
\hline Patient No. & $\begin{array}{c}\text { Race/sex/ } \\
\text { age* }\end{array}$ & $\begin{array}{l}\text { Disease } \\
\text { duration }^{\ddagger}\end{array}$ & SLEDAI $^{s}$ & Therapy" \\
\hline \multicolumn{5}{|l|}{ Severe SLE } \\
\hline 1 & $\mathrm{C} / \mathrm{F} / 34$ & 5 & 30 & None \\
\hline 2 & $\mathrm{C} / \mathrm{F} / 28$ & 0.5 & 32 & None \\
\hline 3 & $\mathrm{C} / \mathrm{F} / 36$ & 3 & 26 & Pred/HC \\
\hline 4 & $\mathrm{~B} / \mathrm{F} / 20$ & 0.5 & 39 & None \\
\hline 5 & $\mathrm{C} / \mathrm{F} / 29$ & 0.5 & 21 & HC/NSAID \\
\hline \multicolumn{5}{|l|}{ Moderate SLE } \\
\hline 6 & $\mathrm{C} / \mathrm{F} / 55$ & 10 & 12 & Pred/HC/NSAID \\
\hline 7 & $\mathrm{~B} / \mathrm{M} / 27$ & 3 & 15 & Pred/HC \\
\hline 8 & $\mathrm{~B} / \mathrm{F} / 38$ & 5 & 13 & HC/NSAID \\
\hline 9 & $\mathrm{~B} / \mathrm{F} / 35$ & 7 & 13 & NSAID \\
\hline \multicolumn{5}{|l|}{ Mild SLE } \\
\hline 10 & $\mathrm{C} / \mathrm{F} / 53$ & 17 & 5 & NSAID/HC \\
\hline 11 & $\mathrm{C} / \mathrm{F} / 37$ & 8 & 3 & $\mathrm{HC}$ \\
\hline 12 & $\mathrm{~B} / \mathrm{F} / 33$ & 9 & 5 & None \\
\hline 13 & $\mathrm{C} / \mathrm{F} / 36$ & 2 & 3 & None \\
\hline 14 & $\mathrm{~B} / \mathrm{F} / 35$ & 4 & 3 & HC/NSAID \\
\hline 15 & $\mathrm{C} / \mathrm{F} / 42$ & 20 & 10 & ASA/Pred/HC \\
\hline \multicolumn{5}{|c|}{ Rheumatoid arthritis } \\
\hline 16 & $\mathrm{C} / \mathrm{F} / 47$ & 12 & Syn" & HC/NSAID \\
\hline 17 & $\mathrm{C} / \mathrm{F} / 63$ & 21 & Syn & Pred/G/NSAID \\
\hline 18 & $\mathrm{C} / \mathrm{F} / 36$ & 3 & Syn & HC/NSAID \\
\hline 19 & $\mathrm{~B} / \mathrm{M} / 47$ & 0.5 & Syn & None \\
\hline 20 & $\mathrm{C} / \mathrm{F} / 23$ & 0.5 & Syn & HC/NSAID \\
\hline
\end{tabular}

* Mean ages (range): severe SLE, 29 yr (20-36); moderately active SLE, 39 yr (27-55); mildly active SLE, 39 yr (33-53); rheumatoid arthritis, $43 \mathrm{yr}$ (23-63). ${ }^{\ddagger}$ Mean disease duration (range): severe SLE, $1.9 \mathrm{yr}(0.5-5)$; moderately active SLE, 6 yr (3-10); mildly active SLE, $10 \mathrm{yr}(2-20)$; rheumatoid arthritis, 7 yr $(0.5-21) .{ }^{8}$ Mean SLEDAI: severe SLE, 29; moderately active SLE, 13; mildly active SLE, 7.

" $A S A$, aspirin; $G$, gold salts; $H C$, hydroxychloro-

quine; NSAID, nonsteroidal antiinflammatory agents; Pred, prednisone. 'Syn, synovitis.

Nonsteroidal antiinflammatory agents and hydroxychloroquine were withheld for $72 \mathrm{~h}$ and $7 \mathrm{~d}$, respectively, before study when clinically feasible. Control populations who were matched for age, sex, and race included: $(a)$ healthy subjects $(n=11)$ and $(b)$ functional class II or III RA $(n=5)$. Table I details the patient and disease control populations, the characteristics of the populations, disease duration, SLEDAI score, and current therapy.

Informed consent to participate in this study and to obtain peripheral venous blood by venipuncture or mononuclear leukocytes by leukopheresis was obtained from subjects and controls. The research protocols and consent forms were approved by the Institutional Review Boards of The Bowman Gray School of Medicine/North Carolina Baptist Hospital and Case Western Reserve University School of Medicine/University Hospitals of Cleveland.

$T$ lymphocyte isolation and phenotypic characterization. $\mathrm{T}$ lymphocytes were isolated and enriched from PBMC by an immunoaffinity column ( R \& D Systems, Inc., Minneapolis, MN) $(16,26)$. Cytofluorographic analysis of $\mathrm{T}$ cells stained with FITC-anti-CD3- $\epsilon$ demonstrated that $95 \pm 0.9 \%$ expressed the $\mathrm{CD} 3$ membrane molecular complex that defines $\mathrm{T}$ lymphocytes.

Cell cultures. PBMC $\left(5 \times 10^{6} / \mathrm{ml}\right)$ were cultured in RPMI 1640 supplemented with $5 \%$ heat-inactivated $\mathrm{AB}$ serum, $10 \mu \mathrm{g} / \mathrm{ml}$ gentamicin, $200 \mathrm{mM} \mathrm{L}$-glutamine, and $10 \mathrm{mM}$ Hepes for $72 \mathrm{~h}$ at $37^{\circ} \mathrm{C}$ in $5 \%$ 
$\mathrm{CO}_{2}$. The cells were harvested, cell viability $\geq 98 \%$ was verified, and $T$ lymphocytes were enriched.

Analysis of $T$ cell plasma membrane-associated protein phosphorylation by two-dimensional SDS-PAGE (2-D PAGE). The capacity of PKA-I to phosphorylate $T$ cell membrane-associated proteins was analyzed by high-resolution 2-D PAGE (27). T cells were gently disrupted and homogenized in isosmolar buffer A ( $5 \mathrm{mM}$ Tris- $\mathrm{HCl}$ [pH 7.2], $250 \mathrm{mM}$ sucrose, $1 \mathrm{mM}$ PMSF, $0.1 \mathrm{mM}$ DTT, $1 \mathrm{mM}$ EDTA) using 30 strokes in a Dounce homogenizer (Kontes Glass Co., Vineland, NJ) to minimize release of the PKA-I isozyme from the membrane (12). T lymphocyte plasma membrane fractions were subsequently isolated by sucrose density gradient centrifugation (12). Marker enzyme assays for 5 ' nucleotidase (plasma membrane), lactic dehydrogenase (cytosol), $\beta$-glucuronidase (lysosome), glucose-6-phosphatase (endoplasmic reticulum), and succinic dehydrogenase (mitochondria) activities demonstrated that the isolated plasma membrane fractions were not contaminated by cytosolic organelles. Plasma membrane $(60 \mu \mathrm{g})$ was suspended in buffer B ( $40 \mathrm{mM}$ Tris- $\mathrm{HCl}$ [pH 7.2], 0.05\% Triton X-100, $100 \mu \mathrm{M}$ RO20-1724 [a cAMP phosphodiesterase inhibitor], 1 mM EGTA, 10 $\mathrm{mM} \mathrm{MgCl} 2,10 \mathrm{mM} \mathrm{NaF}$ ) in the presence of $10 \mu \mathrm{M}$ cAMP and 100 $\mu \mathrm{M}\left[\gamma_{-}{ }^{32} \mathrm{P}\right] \mathrm{ATP}$ (3,000 Ci/mmol; New England Nuclear/Dupont, Wilmington, DE) for 0 and $10 \mathrm{~min}$ at $30^{\circ} \mathrm{C}$. Thus, baseline phosphorylation of membrane-associated proteins is defined as the incorporation of phosphate-32 at $0 \mathrm{~min}$ in the presence of cAMP. In some experiments, the specific PKA peptide inhibitor, $10 \mu \mathrm{M} \mathrm{PKI}_{5-24}$ (Peninsula Labs, Inc., Belmont, CA), was added to the 0-min sample to demonstrate specific inhibition of PKA-catalyzed protein phosphorylation. After incubation, samples were immediately frozen in a methanol/dry ice bath and were lyophilized. The lyophilized samples were redissolved in $100 \mu \mathrm{l}$ of buffer C ( $9.5 \mathrm{M}$ urea, $0.2 \%$ Triton X-100, 1\% DTT, and $0.8 \%$ each of ampholines with pIs of 3.5-10, 5-7, and 4-6 [Pharmacia LKB Biotechnology Inc., Piscataway, NJ]).

The membrane proteins were separated by 2-D PAGE. Samples containing $60 \mu \mathrm{g}$ of protein were loaded onto isoelectric focusing gels, and electrophoresis was carried out for $16 \mathrm{~h}$ at room temperature at $400 \mathrm{~V}$ with $0.1 \mathrm{M} \mathrm{H}_{3} \mathrm{PO}_{4}$ and $0.02 \mathrm{M} \mathrm{NaOH}$ as electrode buffers. Electrophoresis in the second dimension was carried out at $35 \mathrm{~mA}$ per gel. The gels were fixed, dried, and exposed to Kodak X-Omat film at $-70^{\circ} \mathrm{C}$ for up to $28 \mathrm{~d}$. Quantification of phosphate-32 incorporated into proteins was by computerized scanning laser densitometry (26).

To analyze protein phosphorylation stimulated by a purified PKA C-subunit, $50 \mathrm{nM}$ PKA C-subunit was added to $30 \mu \mathrm{g}$ of plasma membrane in buffer B containing $100 \mu \mathrm{M}\left[\gamma^{3}{ }^{32} \mathrm{P}\right]$ ATP $(3,000 \mathrm{Ci} / \mathrm{mmol})$, but without cAMP and RO20-1724, in a total reaction volume of 100 $\mu \mathrm{l}$ for 0 and $10 \mathrm{~min}$ at $30^{\circ} \mathrm{C}$. After incubation, the samples were immediately frozen in a methanol/dry ice bath, lyophilized, and redissolved in buffer C. $30 \mu \mathrm{g}$ of membrane protein was loaded onto isoelectric focusing gels and separated by 2-D PAGE; autoradiographs were exposed for $7 \mathrm{~h}$ at room temperature. In some experiments, quantification of phosphate-32 incorporation into proteins was carried out by cutting the radiolabeled spots out of gels, extracting with $1 \mathrm{ml}$ of Protosol $\left(60^{\circ} \mathrm{C}\right.$, $60 \mathrm{~min}$ ), and measuring in a scintillation counter (Packard Instruments, Meriden, CT).

Analysis of $\left[{ }^{35} S\right]$ methionine-labeled $T$ cell membrane-associated proteins by 2-D PAGE. To establish whether SLE T cells possess the same distribution and amounts of membrane proteins as normal $\mathrm{T}$ cells, $T$ cells were biosynthetically labeled with $\left[{ }^{35} \mathrm{~S}\right]$ methionine, and membrane proteins were analyzed by 2-D PAGE (28). $4 \times 10^{8} \mathrm{~T}$ cells were washed once with cold PBS, once with buffered low-methionine RPMI 1640 containing $2 \%$ dialyzed FCS, and incubated at $20 \times 10^{6} / \mathrm{ml}$ in low-methionine medium at $37^{\circ} \mathrm{C}$ for $30 \mathrm{~min}$. Cells were metabolically labeled with $250 \mu \mathrm{Ci} / \mathrm{ml}$ of Trans $\left[{ }^{35} \mathrm{~S}\right]$ methionine $(>1,000 \mathrm{Ci} / \mathrm{mmol}$; ICN Biomedicals, Inc., Costa Mesa, CA) for $3 \mathrm{~h}$ at $37^{\circ} \mathrm{C}$, washed three times in cold PBS, and resuspended in isosmolar lysis buffer D ( $5 \mathrm{mM}$ Tris- $\mathrm{HCl}[\mathrm{pH} 7.2$ ], $0.05 \%$ Triton $\mathrm{X}-100,250 \mathrm{mM}$ sucrose, $1 \mathrm{mM}$ PMSF, $0.1 \mathrm{mM}$ DTT, and $10 \mu \mathrm{g} / \mathrm{ml}$ each of aprotinin and leupeptin). Membrane proteins were then isolated, and the labeled proteins from $4 \times 10^{8}$ cells were separated by 2-D PAGE. The gels were fixed, dried, and exposed to Kodak X-Omat film at $-70^{\circ} \mathrm{C}$ for $6 \mathrm{~h}$. Quantification of sulfur-35 incorporated into proteins was by computerized scanning laser densitometry (26).

$P K A$ assay. PKA phosphotransferase activity was quantified by measuring the transfer of phosphate-32 from $\left[\gamma_{-}{ }^{32} \mathrm{P}\right]$ ATP to the synthetic heptapeptide, leu-arg-arg-ala-ser-leu-gly $(12,16)$. Total PKA-I and PKA-II phosphotransferase activities and free C-subunit activity were obtained by summing the enzyme activities in each column fraction (vide infra) for PKA-I, PKA-II, and C-subunit and expressing the total activities as picomoles per minute (16). The ratios of PKA-I to PKAII isozyme activity were calculated as described (16).

$\left[{ }^{3} \mathrm{H}\right]$ cAMP-binding assay. Binding of $\left[{ }^{3} \mathrm{H}\right]$ cAMP to the R-subunits of PKA-I and PKA-II was performed by a modified membrane filtration method (12). Binding activity is quantified in femtomoles per milliliter.

Separation of PKA isozymes by tandem column chromatography. T lymphocytes were lysed in buffer E containing $10 \mathrm{mM} \mathrm{K}_{2} \mathrm{HPO}_{4}$ (pH 7.2), $1 \mathrm{mM}$ EDTA, and $0.1 \mathrm{mM}$ DTT at $4^{\circ} \mathrm{C}$ by sonication. Sonication releases the PKA-I isozyme from the membrane into the homogenate. Separation of PKA-I and PKA-II isozymes was performed by tandem DE52 cellulose and CM-Sephadex column chromatography (16). DE52 cellulose retains the holoenzymes; free $\mathrm{C}$-subunits pass through the DE52 cellulose column and are retained on the CM-Sephadex column $(12,16)$.

$1 \mathrm{mg}$ of cellular homogenate was loaded onto a DE52 cellulose column $(1 \mathrm{ml}, 0.8 \mathrm{~cm} \times 4.3 \mathrm{~cm})$ and rinsed with $10 \mathrm{ml}$ of buffer $E$. The column was eluted with a continuous, linear gradient $(0-0.3 \mathrm{M}$ $\mathrm{NaCl}$ ). Fractions $(60 \mu \mathrm{l})$ were assayed for PKA-I and PKA-II phosphotransferase activity after addition of $10 \mu \mathrm{M}$ cAMP and $100 \mu \mathrm{M}$ isobutylmethylxanthine, a phosphodiesterase inhibitor. Free $\mathrm{C}$-subunit was eluted from the CM-Sephadex column $(2 \mathrm{ml}, 0.8 \mathrm{~cm} \times 4.3 \mathrm{~cm})$ with buffer $\mathrm{E}$ containing $0.55 \mathrm{M} \mathrm{NaCl}$ (16). C-subunit phosphotransferase activity was quantified in the absence of cAMP.

Statistics. Statistical significance $(P \leq 0.05)$ was calculated by the paired $t$ test or nonparametric Wilcoxon signed-rank test (Sigma Stat, Jandel Scientific, Corte Madera, CA).

\section{Results}

Diminished PKA-catalyzed protein phosphorylation in SLE T lymphocyte plasma membrane. We tested the hypothesis that reduced PKA-catalyzed protein phosphorylation in SLE T cells is the result of a PKA isozyme deficiency by assaying the capacity of the PKA-I isozyme to phosphorylate membraneassociated proteins in response to cAMP. The representative autoradiographs shown in Fig. 1 compare cAMP-stimulated, PKA-catalyzed phosphorylation of plasma membrane proteins in a subject with severe SLE with that of a healthy control. Neither normal nor SLE T cells possess a constitutive phosphoprotein a at $0 \mathrm{~min}$ (Fig. $1, A$ and $C$ ). However, when compared with the control (Fig. $1 A$ ), T cell membrane from the SLE subject showed no incorporation of phosphate-32 into phosphoproteins $\mathrm{b}$ and $\mathrm{d}$ at $0 \mathrm{~min}$ (Fig. $1 \mathrm{C}$ ). The absence of phosphate32 incorporation into these phosphoproteins was not due to either altered distribution of or the absence of proteins in the plasma membrane of SLE T cells, as determined by silver staining (not shown) and $\left[{ }^{35} \mathrm{~S}\right]$ methionine labeling (Fig. 2). When compared with normal T cells, $\left[{ }^{35} \mathrm{~S}\right]$ methionine-labeled SLE T cells exhibited a similar distribution of and equivalent amounts of membrane proteins by inspection and by laser densitometry, particularly between a pI of 5-6 and $M_{r} s$ of $14,000-69,000$ where the affected substrates are predominantly localized (Figs. 1 and 2). Phosphate-32 incorporation into phosphoprotein $\mathrm{c}$ in SLE T cells (Fig. $1 C$ ) was similar to that in control $\mathrm{T}$ cells (Fig. $1 A$ ).

The addition of cAMP to normal $\mathrm{T}$ cell membrane enhanced 


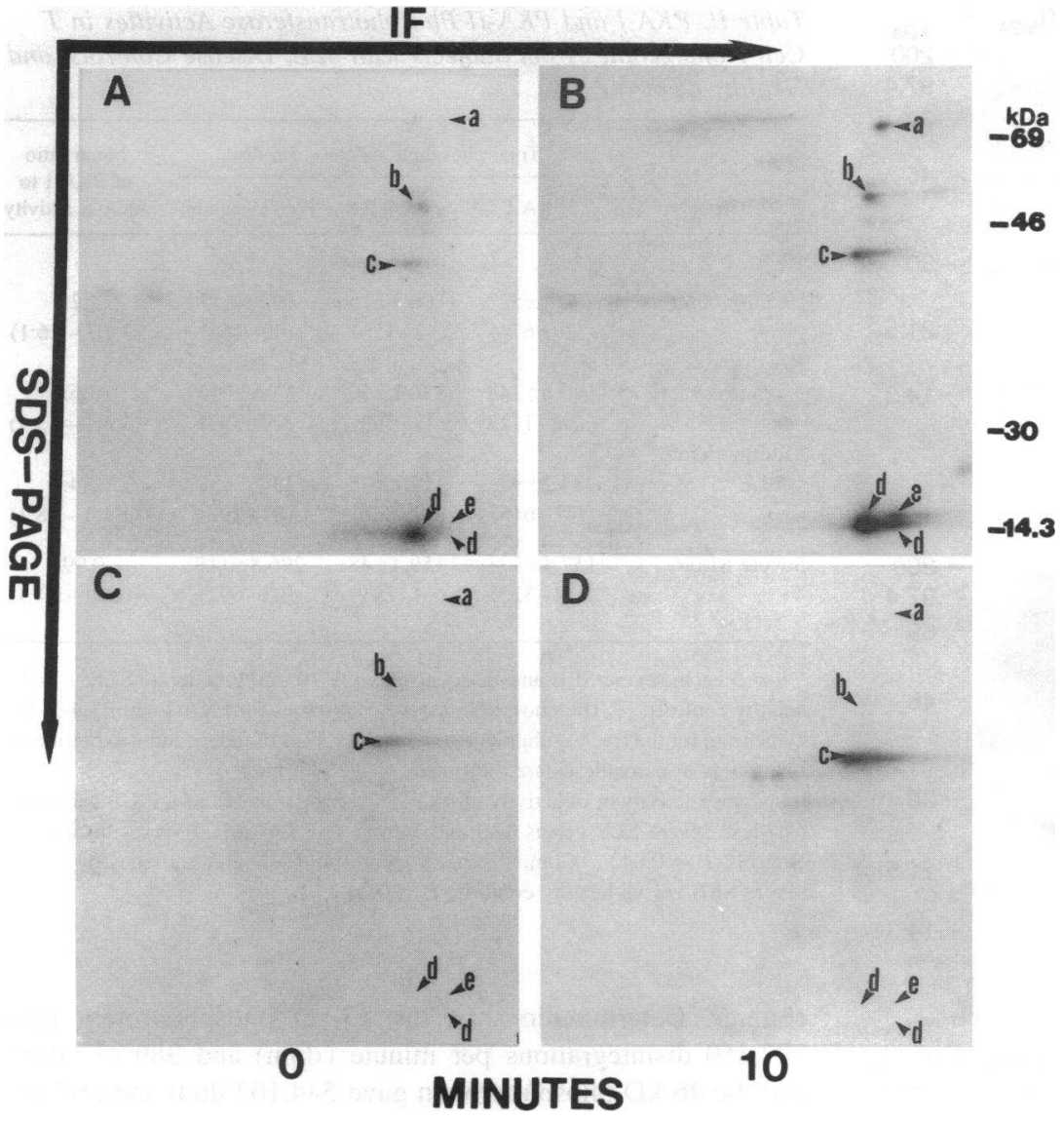

Figure 1. In vitro baseline and cAMP-inducible, PKA-I isozyme-catalyzed phosphorylation of T lymphocyte plasma membrane-associated proteins in a severely active SLE subject and a healthy control by high-resolution 2-D-SDSPAGE. $(A)$ Healthy control, 0 min (membrane $+10 \mu \mathrm{M}$ cAMP $+100 \mu \mathrm{M}$ RO20-1724; baseline protein phosphorylation $) ;(B)$ healthy control, 10 min (membrane $+10 \mu \mathrm{M}$ cAMP +100 $\mu \mathrm{M}$ RO20-1724; cAMP-inducible, PKA-I-catalyzed protein phosphorylation); $(C)$ severe SLE, 0 min (membrane $+10 \mu \mathrm{M}$ cAMP $+100 \mu \mathrm{M}$ RO20-1724; baseline protein phosphorylation); (D) severe SLE, 10 min (membrane $+10 \mu \mathrm{M}$ cAMP + $100 \mu \mathrm{M}$ RO20-1724; cAMP-inducible, PKA-I-catalyzed protein phosphorylation). phosphorylation of phosphoproteins $\mathrm{b}, \mathrm{c}$, and $\mathrm{d}$ and induced phosphorylation of proteins a and e by PKA-I (Fig. $1 B$ ). By contrast, the addition of cAMP failed to result in phosphorylation of phosphoproteins $\mathrm{a}, \mathrm{b}, \mathrm{d}$, or e, but did result in phosphorylation of phosphoprotein c by PKA-I in SLE T cell membrane (Fig. $1 D$ ). Because addition of the specific PKA peptide inhibitor, $\mathrm{PKI}_{5-24}$, to the 0 -min control only partially inhibited baseline phosphorylation of phosphoprotein c (not shown), enhanced phosphorylation of phosphoprotein $\mathrm{c}$ in Fig. $1 \mathrm{D}$ may be the result of PKA-independent protein phosphorylation. Notwithstanding, this diminished PKA-catalyzed phosphorylation of membrane proteins in SLE T cells suggested that PKA-I activity may be diminished.

A potential explanation for the reduced PKA-catalyzed protein phosphorylation in SLE T cells is the presence of proteins already phosphorylated on serine hydroxyl groups. Protein substrates already partially or maximally phosphorylated may be able to accept little, if any, additional phosphate-32 and would, therefore, remain under- or unlabeled. This could lead to an interpretation of underphosphorylation or absent phosphorylation. To determine if SLE T cell membrane proteins could be phosphorylated, we used purified PKA C-subunit. The PKA C-

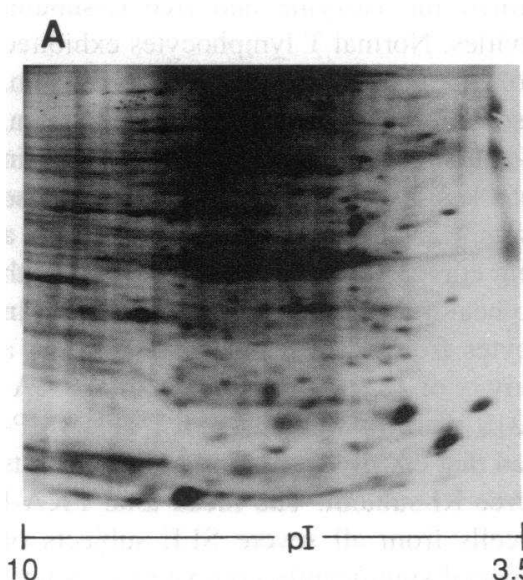

10

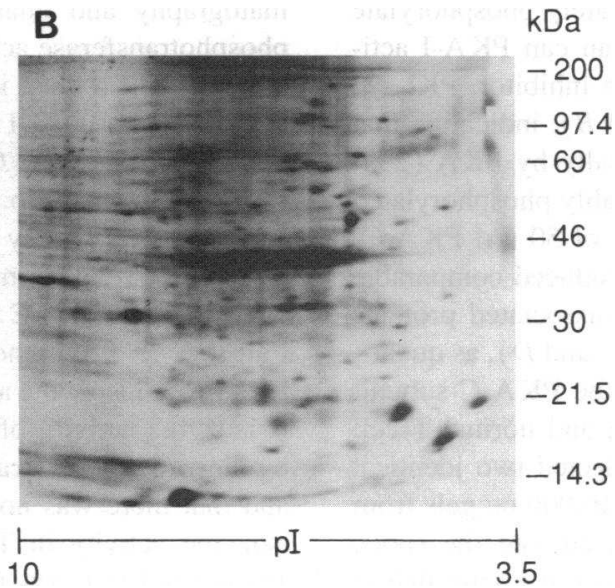

Figure 2. High-resolution 2-D autoradiographs of $\left[{ }^{35} \mathrm{~S}\right]$ methionine-labeled T lymphocyte plasma membrane-associated proteins from a healthy control and a subject with severe SLE. ( $A$ ) Healthy control; $(B)$ severe SLE. 


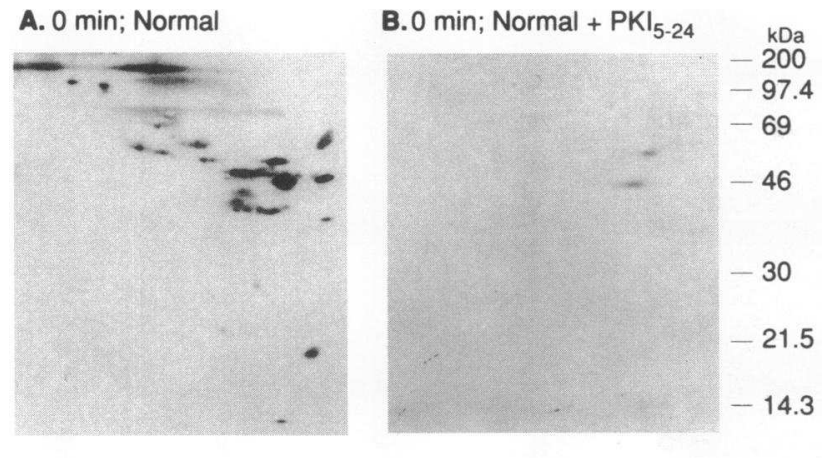

C. Normal + C-Subunit
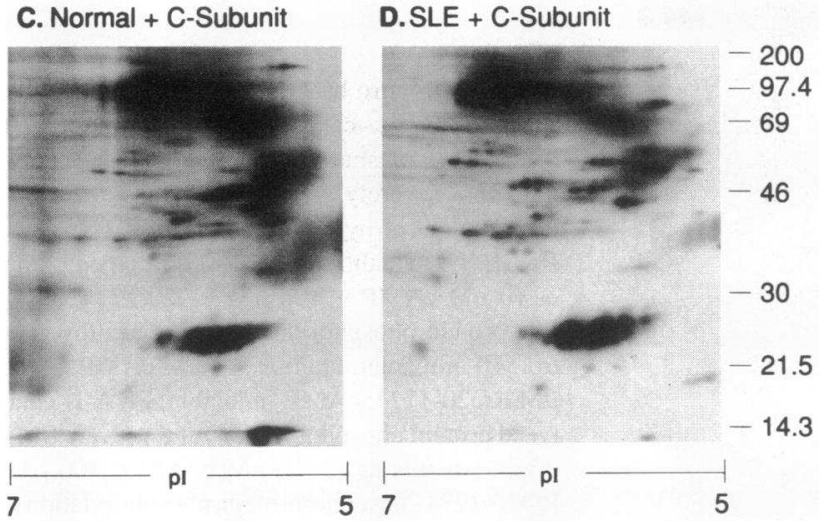

Figure 3. In vitro PKA C-subunit-dependent phosphorylation of plasma membrane-associated proteins from $\mathrm{T}$ cells of healthy and severe SLE subjects by high-resolution 2-D SDS-PAGE. $(A)$ Healthy control, 0 min (membrane $+50 \mathrm{nM}$ PKA C-subunit; baseline protein phosphorylation); $(B)$ healthy control, 0 min (membrane $+50 \mathrm{nM}$ PKA C-subunit + PKA specific peptide inhibitor, $10 \mu \mathrm{M} \mathrm{PKI}_{5-24}$; inhibition of baseline PKA C-subunit-mediated protein phosphorylation); $(C)$ healthy control, 10 min (membrane + $50 \mathrm{nM}$ PKA C-subunit; C-subunit-mediated membrane-associated protein phosphorylation); (D) severe SLE, 10 min (membrane + 50 nM PK A C-subunit; membrane-associated protein phosphorylation by PKA C-subunit).

subunit bypasses the requirement for activation of PKA by cAMP, directly phosphorylating substrates. At 0 min, normal T cell membrane incubated with $50 \mathrm{nM}$ PKA C-subunit produced baseline protein phosphorylation (Fig. $3 A$ ). The pattern of protein phosphorylation in Fig. $3 A$ differs from that in Fig. 1 $A$ because the PKA C-subunit can immediately phosphorylate its substrates to a greater stoichiometry than can PKA-I activated by cAMP. The specific PKA peptide inhibitor, $\mathrm{PKI}_{5-24}$, blocked phosphorylation by $\geq 93 \%$ (Fig. $3 \mathrm{~B}$ ), indicating that the phosphorylation was catalyzed specifically by PKA (29). The remaining phosphoproteins are presumably phosphorylated by another protein kinase(s). The addition of $50 \mathrm{nM}$ PKA Csubunit to plasma membrane for $10 \mathrm{~min}$ produced comparable phosphorylation of most of the membrane-associated proteins from both SLE and control T cells (Fig. 3, $C$ and $D$ ), as quantified by laser densitometry. To verify that the PKA C-subunit phosphorylated membrane proteins in SLE and normal $\mathrm{T}$ cell membranes to an equivalent extent, we selected two identical phosphoproteins located at $M_{\mathrm{r}} \mathrm{s} 25,000$ and 46,000 on gels from severely active SLE and healthy subjects, cut out the spots, and quantified the phosphate-32 incorporation in a scintillation
Table II. PKA-I and PKA-II Phosphotransferase Activities in T Cell Homogenates from Subjects with SLE, Disease Controls, and Healthy Controls

\begin{tabular}{|c|c|c|c|c|}
\hline \multirow[b]{2}{*}{ Group } & \multicolumn{3}{|c|}{ Total phosphotransferase activity } & \multirow{2}{*}{$\begin{array}{c}\text { Mean ratio } \\
\text { of PKA-I to } \\
\text { PKA-II activity }\end{array}$} \\
\hline & PKA-I & PKA-II & Free C-subunit & \\
\hline & & pmol/min & & \\
\hline Healthy controls* & $\begin{array}{l}402.4 \pm 52^{\ddagger} \\
(229-674)^{8}\end{array}$ & $\begin{array}{r}96.3 \pm 15 \\
(43-156)\end{array}$ & $\begin{array}{l}102.6 \pm 17 \\
(40-168)\end{array}$ & $\begin{array}{c}4.2: 1 \\
(3.1: 1-7.6: 1)\end{array}$ \\
\hline $\begin{array}{l}\text { RA disease } \\
\text { controls* }\end{array}$ & $\begin{array}{l}546.6 \pm 148 \\
(162-1117)\end{array}$ & $\begin{array}{l}150.2 \pm 50 \\
(47-399)\end{array}$ & $\begin{array}{r}162 \pm 56 \\
(47-399)\end{array}$ & $\begin{array}{c}3.6: 1 \\
(3.4: 1-6.3: 1)\end{array}$ \\
\hline $\begin{array}{l}\text { Mild/moderate } \\
\text { SLE* }\end{array}$ & $\begin{array}{c}284.2 \pm 97 \\
(47-615)\end{array}$ & $\begin{array}{l}117.2 \pm 48 \\
(38-336)\end{array}$ & $\begin{array}{l}137.3 \pm 37 \\
(67-297)\end{array}$ & $\begin{array}{c}2.4: 1 \\
(1.1: 1-3.8: 1)\end{array}$ \\
\hline Severe SLE* & $\begin{array}{r}157.4 \pm 47^{\prime \prime} \\
(54-320)\end{array}$ & $\begin{array}{l}159.4 \pm 48 \\
(44-291)\end{array}$ & $\begin{array}{c}296.8 \pm 118^{9} \\
(93-692)\end{array}$ & $\begin{array}{c}0.99: 1 \\
(0.6: 1-1.4: 1)\end{array}$ \\
\hline
\end{tabular}

$* n=5$ each, severe SLE and RA controls; $n=10$, mild/moderate SLE; $n=11$, healthy controls. ${ }^{\ddagger}$ The phosphotransferase activities for PKA-I and PKA-II isozymes and for the free $\mathrm{C}$-subunit are the means $\pm S E M$ of independent experiments. Numbers in parentheses are the ranges of the phosphotransferase activity or of activity ratios. "Comparisons of mean PKA-I activities by $t$ test: severe SLE versus healthy controls, $P=0.01$; SLE versus disease controls, $P=0.04$. ' Comparisons of mean free C-subunit activities by $t$ test: severe SLE versus healthy controls, $P=0.04$.

counter. Determinations of the $25-\mathrm{kD}$ phosphoprotein gave 377,450 disintegrations per minute (dpm) and 389,737 dpm, and the $46-\mathrm{kD}$ phosphoprotein gave $544,167 \mathrm{dpm}$ and 565,700 $\mathrm{dpm}$ for SLE and normal T cells, respectively. A variance of $<5 \%$ between the disintegrations per minute of the $25-$ and 46-kD phosphoproteins in normal and SLE T cells would suggest that there is a comparable degree of protein phosphorylation. These findings confirm that phosphorylatable proteins are present in SLE plasma membrane. Moreover, the capacity of C-subunit to phosphorylate proteins on serine residues suggests that the residues are not already partially or maximally phosphorylated by PKA.

Deficiency of PKA-I isozyme activity in SLE T lymphocytes. The impaired PKA-dependent protein phosphorylation in SLE $T$ lymphocyte membrane suggested that a deficiency of PKAI isozyme activity may exist. To quantify PKA activity, we fractionated PKA from homogenates of T cells from SLE and control subjects into its constitutive isozymes, PKA-I and PKAII, by tandem DE52 cellulose and CM-Sephadex column chromatography and quantified the isozyme and free C-subunit phosphotransferase activities. Normal $\mathrm{T}$ lymphocytes exhibited a mean total PKA-I isozyme activity of $402.4 \pm 52 \mathrm{pmol} / \mathrm{min}$, a mean total PKA-II isozyme activity of $96.3 \pm 15 \mathrm{pmol} / \mathrm{min}$, and a mean total free C-subunit activity of $102.6 \pm 17 \mathrm{pmol} / \mathrm{min}$ (Table II). The ratio of PKA-I to PKA-II phosphotransferase activity in this study was 4.2:1 (Table II). The data from a representative experiment comparing $T$ cells from subjects with severe and mild SLE to healthy and RA controls are shown in Fig. 4. The T lymphocytes from a severe SLE subject had a total PKA-I isozyme activity of $225 \mathrm{pmol} / \mathrm{min}$ and a total PKAII isozyme activity of $210 \mathrm{pmol} / \mathrm{min}$ (Fig. $4 \mathrm{~A}$ ). $\left[{ }^{3} \mathrm{H}\right.$ ]cAMPbinding activity indicated that cAMP could bind to RI-subunits and that there was no free RI-subunit. The mean total PKA-I isozyme activity in $\mathrm{T}$ cells from all severe SLE subjects of $157.4 \mathrm{pmol} / \mathrm{min}$ was reduced significantly compared with nor- 

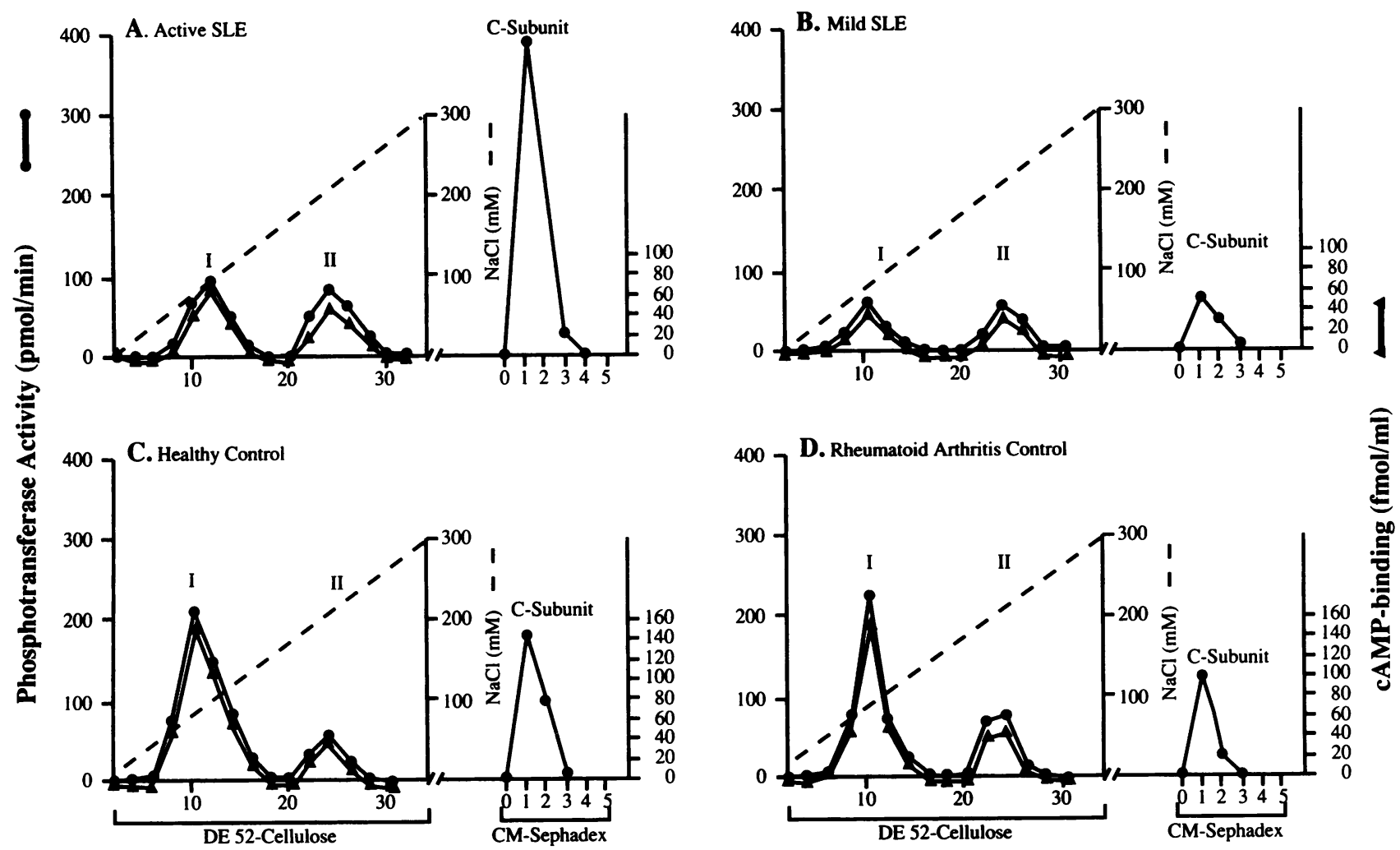

Fraction Number

Figure 4. Isolation and quantification of the PKA-I and PKA-II isozymes and free C-subunit activity from T lymphocytes by tandem DE52 cellulose and CM-Sephadex column chromatography. $(A)$ Severely active SLE; $(B)$ mildly active SLE; $(C)$ healthy control; and $(D)$ rheumatoid arthritis control. Total phosphotransferase activity is quantified in picomoles per minute $(\bullet-\bullet)$ and $\left[{ }^{3} \mathrm{H}\right]$ cAMP-binding activity in femtomoles per milliliter ( - - The coincident peaks of PKA-I and PKA-II isozyme phosphotransferase activities and RI- and RII-subunit cAMP-binding activities indicate that all R-subunits are in the holoenzyme state and that there are no free R-subunits.

mal controls $(P=0.01)$ (Table II). No difference in the PKAII isozyme activities in T cells from severe SLE subjects was observed when compared with controls, however (Table II). $\left[{ }^{3} \mathrm{H}\right]$ cAMP binding to RII-subunits also showed that cAMP could bind to RII-subunits and that there was no free RII-subunit. The activity ratio in Fig. $4 \mathrm{~A}$ was, therefore, reduced to 1.0:1. The mean activity ratio in $T$ cells from all severe SLE subjects was $0.99: 1$, a value substantially below the expected ratio of 4.2:1 in normal $\mathrm{T}$ lymphocytes (Table II).

The reduction of PKA-I isozyme activity was often associated with a rise in total free C-subunit activity in severe SLE. Fig. $4 A$ shows a significantly elevated total free C-subunit activity of $420 \mathrm{pmol} / \mathrm{min}$, a value greatly increased over that found in normal controls (Table II). The mean total free Csubunit activity in T cells for all severe SLE subjects was 296.8 $\mathrm{pmol} / \mathrm{min}(P=0.04$, severe SLE versus healthy controls) ( $\mathrm{Ta}-$ ble II). The deficient PKA-I isozyme activity and elevated Csubunit activity could not be attributed to an effect of a rheumatic illness, for RA controls did not manifest either reduced PKA-I or increased C-subunit activities (Table II).

The ratio of PKA-I to PKA-II activity was also reduced in subjects with mild or moderate SLE disease activity. However, the extent of the reduction in PKA-I activity and, therefore, the activity ratio was more variable (Table II). Fig. $4 B$ illustrates an elution pattern of PKA-I and PKA-II isozymes from an individual with mild, asymptomatic SLE. The activity ratio ap- proximated 1.0:1; however, the total free C-subunit activity was $68 \mathrm{pmol} / \mathrm{min}$, a value considerably below that observed in severe SLE and approximating that found in normal controls (Table II). These data indicate that reduced PKA-I isozyme activity is present in mild or moderate SLE. We observed that an elevated free $C$-subunit activity does not necessarily accompany a reduced ratio of PKA-I to PKA-II isozyme activity.

Effect of in vitro cell culture on deficient PKA-I isozyme activity. To test the hypothesis that deficient PKA-I isozyme activity may be reversible, PBMC from two subjects with untreated, severe SLE and two healthy controls were cultured in vitro for $72 \mathrm{~h}$, the T cells were isolated, and the PKA-I and PKA-II isozyme activities were quantified. No significant change in the ratios was observed after culture (before versus after culture: subject $1,1.0: 1$ vs $0.8: 1$; subject $2,1.1: 1$ vs $1.2: 1$ ). Similarly, no change in the activity ratios of control $\mathrm{T}$ cells before and after culture was demonstrated (data not shown).

\section{Discussion}

Intact $\mathrm{T}$ lymphocytes from subjects with severe SLE disease activity exhibit a striking reduction of cAMP-inducible, PKAcatalyzed protein phosphorylation compared with healthy and rheumatic disease controls (21). The objective of these studies was to test the hypothesis that the disorder of PKA-catalyzed protein phosphorylation in SLE T cells is the result of a PKA 
isozyme deficiency. Using the sensitive technique of high-resolution 2-D PAGE (27), T cells from subjects with severe SLE exhibited reduced PKA-I-catalyzed phosphorylation of membrane-associated proteins compared with healthy controls. This reduction of protein phosphorylation was not attributable to either the absence of membrane-associated proteins or an inability of the proteins to be phosphorylated by PKA. Because the PKA-I isozyme is predominantly associated with the plasma membrane of human $\mathrm{T}$ lymphocytes (12), these results strongly suggested that a deficiency of this PKA isozyme may exist in SLE T cells.

Sequential column chromatography and quantification of the phosphotransferase activities of the PKA-I and PKA-II isozymes in SLE and control $T$ cells demonstrated a significant deficiency of PKA-I isozyme activity. The reduced mean activity ratio of 0.99:1 in T cells from subjects with severe SLE was markedly below the expected activity ratios of 4.2:1 and 3.6:1 found in $\mathrm{T}$ cells from healthy and RA controls, respectively. By contrast, the PKA-II phosphotransferase activities of T cells from severe SLE subjects were similar to those of healthy controls. The deficiency of PKA-I isozyme activity was associated with a significantly increased mean total free C-subunit activity (Table II). The origin of the raised $\mathrm{C}$-subunit activity remains uncertain. However, the heightened activity did not produce indiscriminate protein phosphorylation in SLE T cells, because the purified PKA C-subunit could phosphorylate protein substrates in $\mathrm{T}$ cell membranes from severe SLE subjects to an extent comparable with control $\mathrm{T}$ cells. Taken together with the results of both silver staining and $\left[{ }^{35} \mathrm{~S}\right]$ methionine labeling of membrane-associated proteins that demonstrated no apparent loss of proteins, we conclude that SLE T cell membranes possess proteins which can be phosphorylated by PKA. Thus, the reduced protein phosphorylation appears to be due to a deficiency of PKA-I activity.

Deficient PKA-I isozyme activity was also observed in the $\mathrm{T}$ cells of individuals with mild and moderate disease activity. The mean activity ratio of $2.4: 1$ was also markedly below that of healthy controls. The deficiency was, however, more variable among subjects, and the low isozyme activity was not associated with high free $\mathrm{C}$-subunit activity. By contrast, the mean activity ratio of 3.6:1 in RA controls was within the range observed in healthy controls ( Table II). These findings indicate that a range of PKA-I isozyme deficiency exists in SLE T cells, the most pronounced being in $\mathrm{T}$ cells from persons with severe SLE. Nevertheless, very low PKA-I activities can be present in SLE subjects with mild disease activity, as shown in Fig. 4; this observation suggests that deficient PKA-I activity is not necessarily associated only with very active SLE disease activity. That a deficiency of the isozyme is present in $\mathrm{T}$ cells during relative disease inactivity may explain, in part, the persistent suppressor cell dysfunction and altered capping of surface molecules observed previously $(1,9,23)$.

The altered phosphorylation in SLE $T$ lymphocytes does not appear to be attributable to circulating serum factors, such as immune complexes or anti-T cell autoantibodies, that can be present in the serum of ill SLE subjects (26). Moreover, our results herein demonstrate that the deficiency of PKA-I isozyme activity cannot be reversed by in vitro culture of SLE $T$ cells. This finding is in agreement with our previous observation that $T$ cells from active SLE subjects cultured in vitro exhibited a persistent reduction of PKA-catalyzed protein phosphorylation (26). Taken together, these findings militate against the proposition that binding of an extrinsic serum factor(s) to $T$ cells induces aberrant signal transduction via the AC/cAMP/ PKA pathway in SLE.

Although the etiology of the PKA-I isozyme deficiency remains to be determined, several potential mechanisms could be operative. First, persistent T cell activation (7) observed during active SLE could cause ongoing activation of PKA-I, resulting in diminished isozyme activity and elevated free $\mathrm{C}$ subunit activity. Several observations make this mechanism unlikely. Our recent demonstration that normal human $\mathrm{T}$ lymphocytes activated in vitro via the receptor agonists, anti-CD3- $\epsilon$ and recombinant $\mathrm{IL}-1 \alpha$, exhibit rapid activation of the PKA-I isozyme and elevation of free C-subunit activity within 5 min also found that isozyme activity returned to baseline by $60 \mathrm{~min}$ (16). In addition, normal $\mathrm{T}$ cells that are persistently activated in vitro by $\mathrm{IL}-2$ and are predominantly in the $S$ phase of the cell cycle exhibit a reduced PKA-I isozyme activity and, therefore, a reduced activity ratio of PKA-I to PKA-II isozymes. However, PKA-I activity and, therefore, the reduced activity ratio return to preactivation levels and a ratio of 4.0:1 within hours after removing $I L-2$ and permitting the cells to return to the $G_{1}$ phase of the cell cycle (16). These observations in healthy $T$ cells demonstrate that PKA-I activity appears to be associated with the phase of the cell cycle.

By contrast, $T$ cells from subjects with severe SLE cultured in vitro in the absence of mitogens or antigens for up to $72 \mathrm{~h}$ failed to reverse the PKA-I isozyme deficiency as might be expected if the deficiency were the result of chronic cellular activation. This finding may explain the persistent reduction of PKA-catalyzed protein phosphorylation observed in SLE T cells cultured in vitro (26).

In some cases, reduced PKA-I activity may not be associated with cellular activation and the cell cycle, however. The relationship between PKA-I activity and the cell cycle is not observed in malignant cell lines. In these cell lines, which are predominantly in logphase ( $\mathrm{S}$ phase) growth, PKA-I is the principal isozyme detected, and its levels are either physiologic or increased (30). In particular, malignant wild-type S49 murine lymphoma cells and human CEM-SS CD4 ${ }^{+}$leukemic cells are rapidly proliferating cell lines that exclusively express physiologic levels of the PKA-I isozyme despite the logphase growth of cells $(31,32$, and our unpublished data). Thus, it seems unlikely that $\mathrm{T}$ cell activation explains the deficient PKA-I activity in SLE T cells.

A second potential mechanism that could produce persistently low levels of PKA-I activity is an agonist-independent stimulation of AC. However, there are several reasons that also militate against this mechanism. Ongoing agonist-independent activation of $\mathrm{AC}$ would be expected to produce elevated levels of intracellular cAMP in SLE T lymphocytes. However, we and others have found that intracellular cAMP levels in SLE T cells are similar to those of normal controls $(8,33)$. Moreover, we have shown previously in normal $\mathrm{T}$ cells that persistent activation of AC by forskolin and cholera toxin elevates cAMP levels, resulting in occupancy of the cAMP-binding sites of both the RI- and RII-subunits of the PKA-I and PKA-II isozymes as gauged by $\left[{ }^{3} \mathrm{H}\right]-8-\mathrm{N}_{3}-\mathrm{cAMP}$ photoaffinity labeling (34). Thus, persistent activation of AC, leading to increased cAMP levels and occupancy of R-subunit cAMP-binding sites, would be expected to activate both the PKA-I and PKA-II isozymes. Our findings herein indicate only reduced activity of the PKA-I isozyme. Finally, altered levels of guanyl nucleotide-binding 
proteins (i.e., $\mathbf{G}$ proteins) or mutations of $\mathbf{G}$ protein subunits have been identified and associated with disease (35). Mutations of the $\alpha_{\mathrm{s}}$ gene can produce constitutive activation of AC. However, the absence of any such observations in human $T$ lymphocytes to date would not support the notion of an agonistindependent activation of $\mathrm{AC}$ due to its constitutive activation.

A third potential mechanism is a deficiency of RI-subunit protein, which could leave an excess of unbound or free Csubunit. This is a viable mechanism. However, why free Csubunit activities are elevated in T cells from many severe SLE subjects but not in those from mild SLE subjects with deficient PKA-I activity remains to be determined.

Yet a fourth potential mechanism is a mutation in either the RI- or C-subunits. Such a mutation may alter the apparent association constant $\left(K_{\mathrm{a}}\right)$ of the RI-subunit for cAMP or of the $\mathrm{C}$-subunit for the R-subunit. This, too, is a viable mechanism, for a mutation(s) of either the R- or C-subunit could diminish the activity of the PKA-I isozyme. There are precedents for such mutations. Variants of the S49 mouse lymphoma cell line express discrete single-nucleotide base mutations in or about the cAMP-binding sites of R-subunits that impede occupancy of these sites, significantly increasing the apparent $K_{\mathrm{a}}$ for halfmaximal PKA activity when compared with wild-type cells (36). Similarly, a single amino acid change in the cAMP-binding site of the R-subunit induced by site-directed mutagenesis also resulted in reduced cAMP binding, yielding a markedly increased apparent $K_{\mathrm{a}}$ for cAMP analogues (37). In addition, a spontaneous mutant of a yeast PKA C-subunit has been identified that exhibited a markedly reduced affinity for the R-subunit, a several-fold increase in its apparent Michaelis constant for both ATP and a peptide substrate, but no change in its catalytic rate $(38)$.

Because PKA is the only known intracellular receptor for cAMP $(10,11)$ and is essential for the phosphorylation of particular transcription factors that regulate gene expression (39), impaired PKA-dependent protein phosphorylation due to deficient PKA-I isozyme activity could alter homeostasis regulated by cAMP $(13,17)$ and impede gene transcription, contributing to $\mathrm{T}$ cell immune effector dysfunctions in SLE (1).

\section{Acknowledgments}

We thank Mr. A. Berrada, Ms. S. Khan, and Mr. R. Papay for excellent technical support and the many patients without whose cooperation this study could not have been performed.

This study was supported by National Institutes of Health grants AR-39501 and M01-RR 00080, by a Biomedical Science Grant from the Arthritis Foundation, and by the Greater Cleveland Chapter of the Lupus Foundation of America.

\section{References}

1. Kammer, G. M., and R. L. Stein. 1990. T lymphocyte immune dysfunctions in systemic lupus erythematosus. J. Clin. Lab. Med. 115:273-282.

2. Tsokos, G. C. 1991. Biochemical and molecular abnormalities in the pathogenesis of systemic lupus erythematosus. Clin. Exp. Rheumatol. 9:533-539.

3. Suciu-Foca, N., J. Buda, T. Thiem, and K. Reemtsma. 1974. Impaired responsiveness of lymphocytes in patients with systemic lupus erythematosus. Clin. Exp. Immunol. 18:295-301.

4. Abdou, N. I., A. Sagawa, E. Pascual, J. Hebert, and S. Sadeghee. 1976 Suppressor $\mathrm{T}$ cell abnormality in idiopathic systemic lupus erythematosus. Clin. Immunol. Immunopathol. 6:192-199.

5. Fauci, A., A. Steinberg, B. Haynes, and G. Whalen. 1978. Immunoregulatory aberrations in systemic lupus erythematosus. J. Immunol. 121:1473-1479.

6. Gottlieb, A. B., R. G. Lahita, N. Chiorazzi, and H. G. Kunkel. 1979.
Immune function in systemic lupus erythematosus. Impairment of in vitro T-cell proliferation and in vivo antibody response to exogenous antigen. J. Clin. Invest. 63:885-892.

7. Inghirami, G., J. Simon, J. E. Balow, and G. C. Tsokos. 1988. Activated T lymphocytes in the peripheral blood of patients with systemic lupus erythematosus induce B cells to produce immunoglobulin. Clin. Exp. Rheumatol. 6:269-276.

8. Mandler, R., R. E. Birch, S. Polmar, G. M. Kammer, and S. A. Rudolph 1982. Abnormal adenosine-induced immunosuppression and cAMP metabolism in T lymphocytes of patients with systemic lupus erythematosus. Proc. Natl. Acad. Sci. USA. 79:7542-7546.

9. Kammer, G. M., R. E. Birch, and S. Polmar. 1983. Impaired immunoregulation in systemic lupus erythematosus: defective adenosine-induced suppressor $\mathrm{T}$ lymphocyte generation. J. Immunol. 130:1706-1712.

10. Corbin, J. D., P. H. Sugden, T. M. Lincoln, and S. L. Keely. 1977 Compartmentalization of adenosine $3^{\prime}: 5^{\prime}$-monophosphate and adenosine $3^{\prime}: 5^{\prime}$ monophosphate-dependent protein kinase in heart tissue. J. Biol. Chem. 252:3854-3861.

11. Edelman, A. M., D. K. Blumenthal, and E. G. Krebs. 1987. Protein serine/ threonine kinases. Annu. Rev. Biochem. 56:567-613.

12. Hasler, P., J. J. Moore, and G. M. Kammer. 1992. Human T lymphocyte cAMP-dependent protein kinase: subcellular distributions and activity ranges of type I and type II isozymes. FASEB (Fed. Am. Soc. Exp. Biol.) J. 6:2735-2741.

13. Kammer, G. M. 1988. The adenylate cyclase-cAMP-protein kinase A pathway and regulation of the immune response. Immunol. Today 9:222-229.

14. Klausner, R. D., and L. E. Samelson. 1991. T cell antigen receptor activation pathways: the tyrosine kinase connection. Cell. 64:875-878.

15. Berry, N., and Y. Nishizuka. 1990. Protein kinase $C$ and T cell activation. Eur. J. Biochem. 189:205-214.

16. Laxminarayana, D., A. Berrada, and G. M. Kammer. 1993. Early events of human $\mathrm{T}$ lymphocyte activation are associated with type I protein kinase A activity. J. Clin. Invest. 92:2207-2214.

17. Kammer, G. M., C. A. Boehm, S. A. Rudolph, and L. A. Schultz. 1988. Mobility of the human T lymphocyte surface molecules CD3, CD4 and CD8: regulation by a cAMP-dependent pathway. Proc. Natl. Acad. Sci. USA. 85:792796.

18. Sugiyama, H., P. Chen, M. Hunter, R. Taffs, and M. V. Sitkovsky. 1992 The dual role of the cAMP-dependent protein kinase $\mathrm{C}$ alpha subunit in T-cell receptor-triggered T-lymphocytes effector functions. J. Biol. Chem. 267:2525625263.

19. Averill, L. E., R. L. Stein, and G. M. Kammer. 1988. Control of human T-lymphocyte interleukin-2 production by a cAMP-dependent pathway. Cell. Immunol. 115:88-99.

20. Novak, T. J., and E. V. Rothenberg. 1990. cAMP inhibits induction of interleukin 2 but not of interleukin 4 in T cells. Proc. Natl. Acad. Sci. USA. 87:9353-9357.

21. Hasler, P., L. A. Schultz, and G. M. Kammer. 1990. Defective cAMPdependent phosphorylation of intact $T$ lymphocytes in active systemic lupus erythematosus. Proc. Natl. Acad. Sci. USA. 87:1978-1982.

22. Kammer, G. M. 1983. Impaired T cell capping and receptor regeneration in active systemic lupus erythematosus. Evidence for a disorder intrinsic to the T lymphocyte. J. Clin. Invest. 72:1686-1697.

23. Kammer, G. M., and E. Mitchell. 1988. Impaired mobility of human $\mathrm{T}$ lymphocyte surface molecules during inactive systemic lupus erythematosus. Arthritis Rheum. 31:88-98.

24. Tan, E. M., A. S. Cohen, F. Fries, A. T. Masi, D. J. McShane, N. F Rothfield, J. G. Schaller, N. Talal, and R. J. Winchester. 1982. The 1982 revised criteria for the classification of systemic lupus erythematosus. Arthritis Rheum. 15:1271-1275.

25. Bombardier, C., D. D. Gladman, M. B. Urowitz, D. Caron, C. H. Chang, and Committee on Prognosis Studies in SLE. 1992. Derivation of the SLEDAI. A disease activity index for lupus patients. Arthritis Rheum. 35:630-640.

26. Kammer, G. M., T. M. Haqqi, P. Hasler, and C. J. Malemud. 1993. The effect of circulating serum factors from patients with systemic lupus erythematosus on protein kinase A (PKA) activity and PKA-dependent protein phosphorylation in T lymphocytes. Clin. Immunol. Immunopathol. 67:8-16.

27. O'Farrell, P. H. 1975. High resolution two-dimensional electrophoresis of proteins. J. Biol. Chem. 250:4007-4021.

28. Steinberg, R. A. 1983. Radiolabeling and detection methods for studying metabolism of regulatory subunit of cAMP-dependent protein kinase $I$ in intact cultured cells. Methods Enzymol. 99:233-243.

29. Kemp, B. E., R. B. Pearson, and C. M. House. 1991. Pseudosubstratebased peptide inhibitors. Methods Enzymol. 201:287-304.

30. Cho-Chung, Y. S. 1990. Role of cyclic AMP receptor proteins in growth, differentiation, and suppression of malignancy: new approaches to therapy. Cancer Res. 50:7093-7100.

31. Steinberg, R. A., and D. A. Agard. 1981. Turnover of regulatory subunit of cyclic AMP-dependent protein kinase in S49 mouse lymphoma cells. J. Biol. Chem. 256:10731-10734.

32. Steinberg, R. A., and D. A. Agard. 1981. Studies on the phosphorylation 
and synthesis of type I regulatory subunit of cylic AMP-dependent protein kinase in intact S49 mouse lymphoma cells. J. Biol. Chem. 256:11356-11364.

33. Phi, N. C., A. Takats, V. H. Binh, C. V. Vien, R. Gonzalez-Cabello, and P. Gergely. 1989. Cyclic AMP level of lymphocytes in patients with systemic lupus erythematosus and its relation to disease activity. Immunol. Lett. 23:61-64.

34. Kammer, G. M., C. Boehm, and S. A. Rudolph. 1986. Role of adenylate cyclase in human T-lymphocyte surface antigen capping. Cell. Immunol. 101:251258.

35. Weinstein, L. S., and A. Shenker. 1993. G protein mutations in human disease. Clin. Biochem. 26:333-338.

36. Steinberg, R. A., K. B. Gorman, D. Ogreid, S. O. Doskeland, and I. T. Weber. 1991. Mutations that alter the charge of type I regulatory subunit and modify activation properties of cyclic AMP-dependent protein kinase from S49 mouse lymphoma cells. J. Biol. Chem. 266:3547-3553.

37. Bubis, J., J. J. Neitzel, L. D. Saraswat, and S. S. Taylor. 1988. A point mutation abolishes binding of cAMP to site A in the regulatory subunit of cAMPdependent protein kinase. J. Biol. Chem. 263:9668-9673.

38. Levin, L. R., J. Kuret, K. E. Johnson, S. Powers, S. Cameron, T. Michaeli, M. Wigler, and M. J. Zoller. 1988. A mutation in the catalytic subunit of cAMPdependent protein kinase that disrupts regulation. Science (Wash. DC). 240:6870.

39. Rehfuss, R. P., K. M. Walton, M. M. Loriaux, and R. H. Goodman. 1991. The cAMP-regulated enhancer-binding protein ATF-1 activates transcription in response to cAMP-dependent protein kinase A. J. Biol. Chem. 266:18431-18434. 